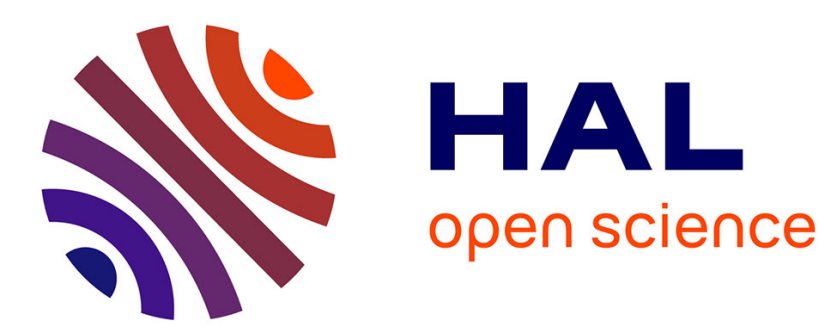

\title{
Contribution to solar concentrators design for photovoltaic application
}

A. Ahaitouf, Christyves Chevallier, Jean-Paul Salvestrini, A. Ougazzaden

\section{To cite this version:}

A. Ahaitouf, Christyves Chevallier, Jean-Paul Salvestrini, A. Ougazzaden. Contribution to solar concentrators design for photovoltaic application. 2nd International Renewable and Sustainable Energy Conference IRSEC, Oct 2014, Ouarzazate, Morocco. 10.1109/IRSEC.2014.7059848 . hal-01117218

\author{
HAL Id: hal-01117218 \\ https://hal.science/hal-01117218
}

Submitted on 17 Apr 2020

HAL is a multi-disciplinary open access archive for the deposit and dissemination of scientific research documents, whether they are published or not. The documents may come from teaching and research institutions in France or abroad, or from public or private research centers.
L'archive ouverte pluridisciplinaire HAL, est destinée au dépôt et à la diffusion de documents scientifiques de niveau recherche, publiés ou non, émanant des établissements d'enseignement et de recherche français ou étrangers, des laboratoires publics ou privés. 


\section{Contribution to solar concentrators design for photovoltaic application}

\author{
Ali Ahaitouf ${ }^{1}$ \\ Georgia Tech Lorraine \\ UMI 2958 GT-CNRS \\ Metz, France \\ Email: \\ ali.ahaitouf@georgiatech-metz.fr
}

\author{
Christyves Chevallier ${ }^{2}$, Jean Paul Salvestrini ${ }^{2}$ \\ Université de Lorraine \\ LMOPS \\ Metz, France \\ Emails: \\ cchevallier@georgiatech-metz.fr, \\ salvestr@metz.supelec.fr
}

Elect

Abdallah Ougazzaden

Georgia Institute of Technology

Georgia Tech Lorraine, UMI2958 GT-CNRS

Metz, France

Email:

abdallah.ougazzaden@georgiatech-metz.fr

\begin{abstract}
Some properties of solar concentrator based on a Fresnel lens, a compound parabolic concentrator (CPC) and a cone are investigated. The effect of the source incidence angle on the focal point of the lens is highlighted and a procedure for a cone design is presented. This later defines also the sizes of the primary optic
\end{abstract}

Keywords-Solar concentrator, compound parabolic concentrator, CPC, cone concentrator, Fresnel lens

\section{INTRODUCTION}

Solar energy is today the most promising renewable source of energy and offers great potential in terms of supplying the world energy needs. Its development is still limited by the huge initial cost of the solar systems. Over the last few decades, an important attention has been devoted by governments, academics and industrials to sustain the emergency of the new energies to reduce the dependencies on fossil fuels and also to improve the energy efficiencies.

Due to recent development of solar cells technologies, III$\mathrm{V}$ semiconductors, multijunction solar cells emerge as a more promising solution for high energy efficiencies [1]. In fact, a multijunction solar cell contains several $\mathrm{p}-\mathrm{n}$ junctions that are each tuned to absorb a different wavelength of light, such as UV, infrared, and visible light (see for instance Figure 1), and hence the efficiency is increased and consequently the major part of the solar radiations is transformed to electricity[2].

However the cost of this kind of cells, still hindering their use on a large scale and the big challenge is the reduction of the cost per kWh by minimizing the amount of semiconductor material needed in each solar module. That's why photovoltaic under concentration (CPV) concentrates a lot of researcher efforts today. In fact using optical elements to concentrate the sun light can help to achieve the price requirement considering that the cost of the optical elements such as mirrors, lenses and so can highly soften the cost of the materials for solar cells. Several solar concentrators, including Fresnel lenses, compound parabolic concentrator (CPC) and other shapes have been studied in the past and have recently regain much attention to their potential use in CPV systems [3], [4], [5], [6],

\footnotetext{
${ }^{1}$ Permanent adress: FST-USMBA, P. O. Box 2202 FEZ-MOROCCO

${ }^{2}$ Also with the UMI2958 GT-CNRS
}

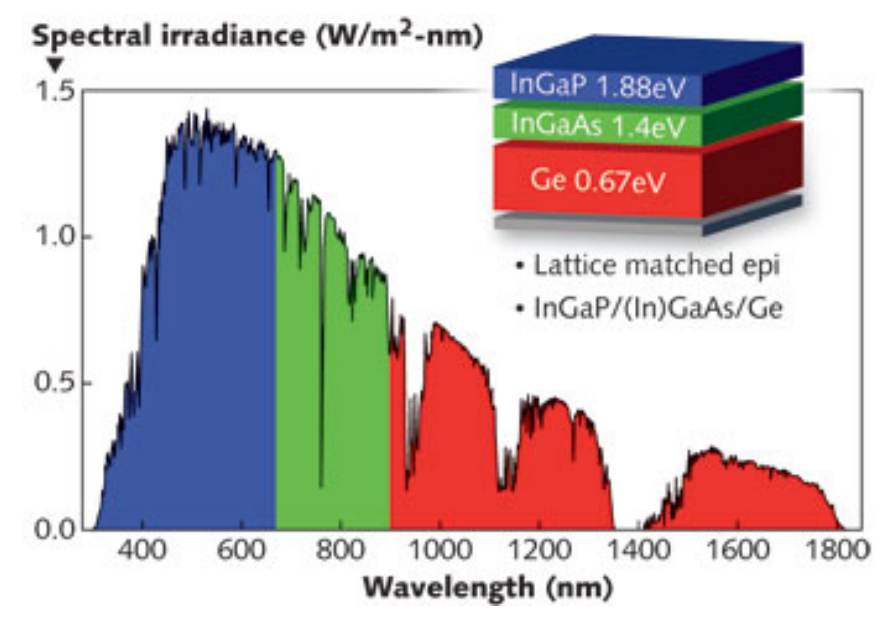

Fig. 1: Solar spectrum and a three potential materials for multijunction solar cells

[7]. CPV systems generally used primary and secondary optics to both increase efficiencies and light collection. The Fresnel lens is the most popular primary element and is associated with a secondary one as CPC, cone or even dome shaped lenses [8]. The primary and secondary element arrangement is highly sensitive and must be studied carefully in order to optimize the solar light collection and hence to improve the efficiency of the solar cell.

In this paper we present a study of a concentrator system formed by a Fresnel lens and a secondary CPC or a cone. We investigate both the secondary element placement and the effect of incidence angle on the focal point as well as how to design an efficient cone for solar concentrator given the sizes of the primary lens. All our results are performed by simulations using the ray tracing TracePro software.

The reminder of the paper is organized as follow, in the second section we discuss the Fresnel lens concentration and the displacement of the focal point related to the incidence angle. The third section will be devoted to the lens and CPC association results and the fourth part concerns the cone design and optimization. A conclusion dressing the major result will close the document. 


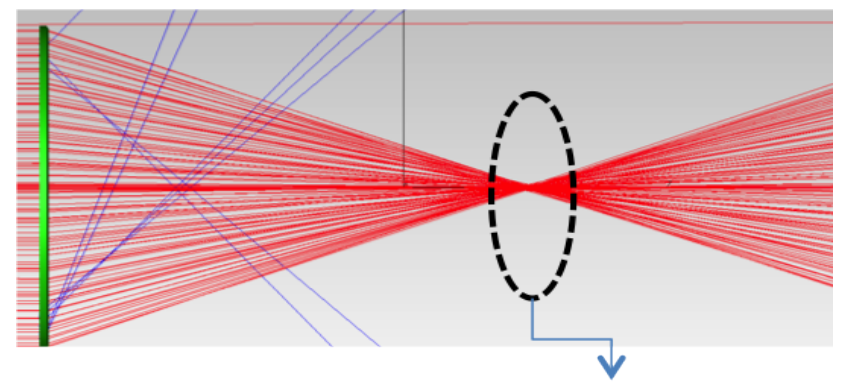

(a) Focal point

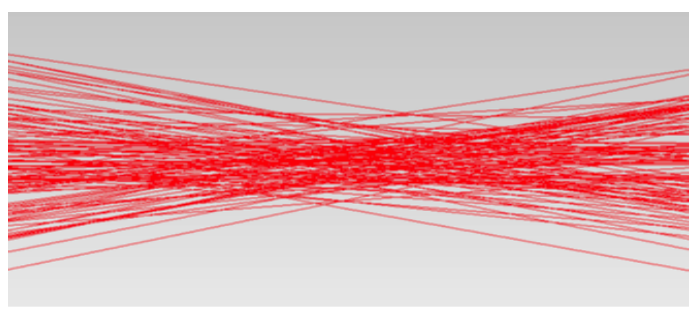

(b) Zooming the focal point

Fig. 2: Only one Fresnel lens

\section{FRESNEL LENS}

The focusing properties of a refracting surface is generally defined by its contour. That's why the Fresnel lens used a set of coaxial annular cylinder materials having a prism-like strictly controlled shape. This kind of lens highly reduce the body material and consequently the absorptions losse and the cost [5]. We have considered a Fresnel lens with $100 \mathrm{~mm}$ diameter, $150 \mathrm{~mm}$ focal distance. We first investigate the focal point size. Figure 2 shows the simulation results and clearly highlights the problem of a large focus point (see fig. 2b). On fig. 2a, there are some lost (blue rays) light rays due to the geometry of the lens.

This large size of the focus point can probably be improved by using some achromatic lenses or by optimizing the grooves forming the Fresnel lens and also by choosing higher material qualities. This way the cost and the competitive aspect can be altered. Nevertheless these effects must be taken into account in the whole concentrator system engineering. That is why most of the solar concentrator uses a secondary element in order to efficiently collect the light.

In order to size the secondary element, we have also investigated the focal point displacement versus the incidence angle, and for three focal distances 150, 200 an $250 \mathrm{~mm}$. Figure 3 shows the simulation results and clearly indicates that larger is the focal distance, larger is the displacement of the focal point and larger must be the secondary element if the tracking solar system is not so perfect that the setup stays continuously perpendicular to the sun rays.

\section{FRESNEL AND CPC AsSOCIATION}

The CPC is the nearest ideal concentrator, consisting of parabolic reflectors which funnel the radiations from the aperture to the absorber. The design of a CPC is widely described

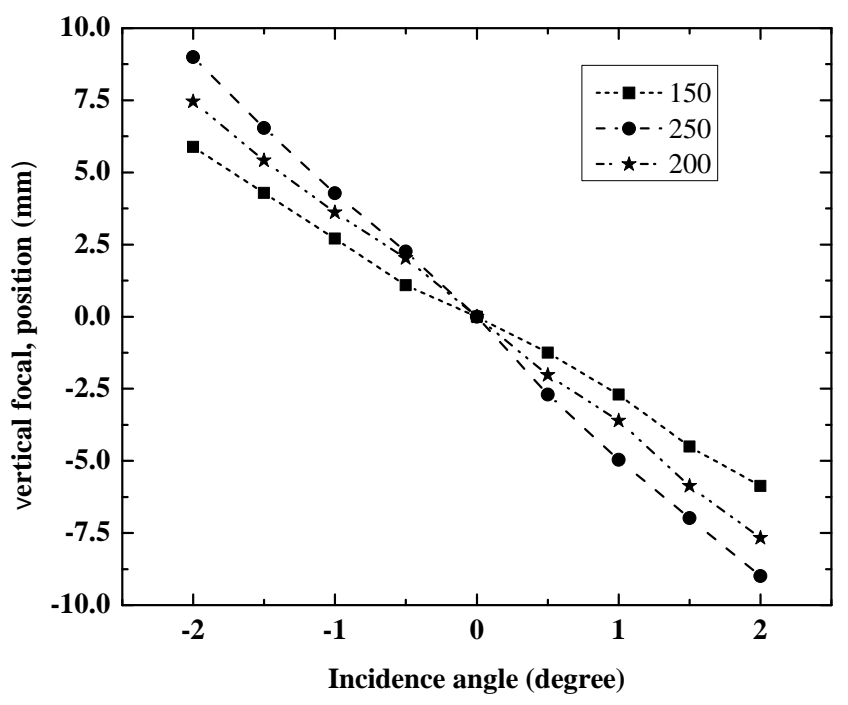

Fig. 3: Displacement of the focal point versus the incidence angle

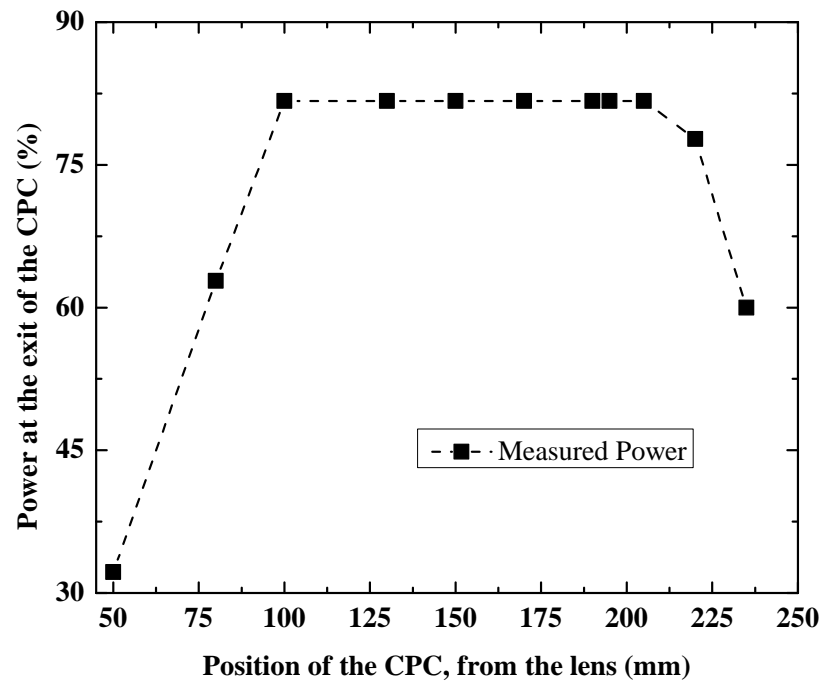

Fig. 4: Power at the exit of the CPC

in the literature, see for instance ref [9]. A CPC is generally defined by its entrance acceptance angle and his exit radius defined by the size of the absorber. The length and the aperture are then directly determined when these two parameters are known [9].

After having characterized the Fresnel lens we have associated a CPC and optimized its position to get the maximum power transmission at its exit. The lens used here has a focal length of $130 \mathrm{~mm}$ and a diameter of $100 \mathrm{~mm}$ and the CPC has an aperture and exit radius of 17 and $3.5 \mathrm{~mm}$ respectively and a length of $44.2 \mathrm{~mm}$. Figure 4 shows that the power at the exit of the CPC is constant over a large interval (around 100mm). This is due to efficiency of the CPC in the light concentration. The major problem of the CPC lies with the exit beam which leaves with larger, near $90^{\circ}$ angles with the optical axes, which 
TABLE I: Evolution of the power at the exit of the CPC versus the incidence angle

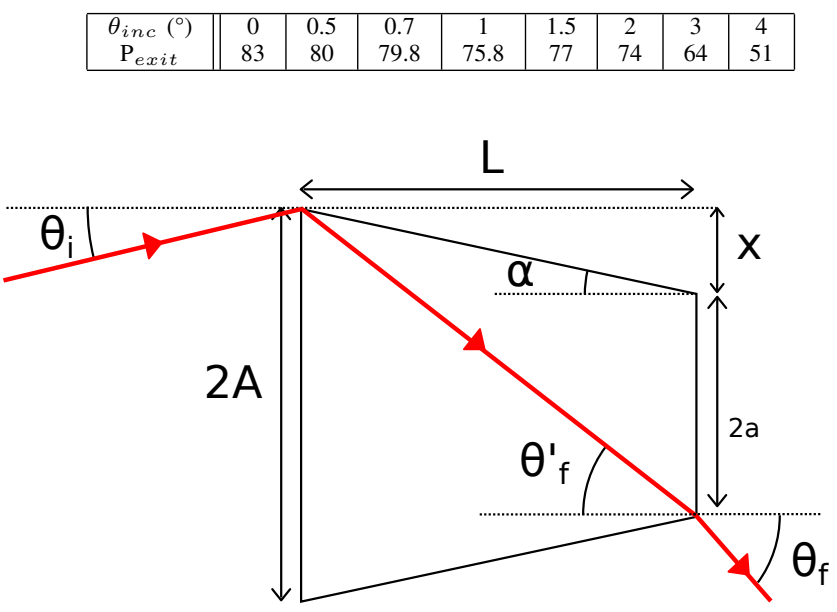

Fig. 5: Scheme of the cone with the edge ray.

make them difficult to touch the absorber. We have also studied the acceptance angle of the association of the Fresnel lens with the CPC. This is defined as the angle for which the exit power is still greater or equal to $80 \%$ of the incidence power. Table I shows the variation of the exit power at the end of the CPC. Here the acceptance angle is limited to $0.5^{\circ}$ which is small and then the setup needs a well convenient solar tracking. Giving these results and taking into account the fact that the CPC is a complex geometrical shape to manufacture, its use in a low cost solar concentrator setup is not optimal.

\section{FRESNEL LENS WITH A CONE}

As a second stage concentrator, it is possible to use a more basic geometrical shape than CPC. Conical collectors have already been studied in details[10], [12] for solar concentrator setups with the absorber directly at its output and output angles as large as $90^{\circ}$. A cone collector has also been studied to collect light with a concentration ratio up to 2000 with a maximum output angle of $28.7^{\circ}[11]$. Cone collectors can thus be efficiently used as a secondary optic in concentrator setup. We present here a rigorous study of the cone design to take into account the input angle defined by the Fresnel lens and the output angle defined by the absorber.

The design parameters for a simple cone (Figure 5) are only its length $L$, its output diameter $2 a$ and its input diameter $2 A$. The angle of the cone $\alpha$ is derived from these parameters.

Inside the cone of optical index $n_{c}$, the input and output angles $\left(\theta_{i}\right.$ and $\left.\theta_{f}\right)$ are subjected to refraction and become $\theta_{i}^{\prime}$ and $\theta_{f}^{\prime}$ respectively. The reflection inside the cone deflect the rays away by an angle $2 \alpha$. To be able to collect all the rays focalized by the Fresnel lens and deflect them with a maximum angle of $\theta_{f}$, the cone angle $\alpha$ is defined by a maximum value $\alpha_{\max }=\left(\theta_{f}^{\prime}-\theta_{i}^{\prime}\right) / 2$. This first design rule gives a limitation to the Fresnel lens radius $r$ and focal distance $f$ since $\theta_{i}=$ $\arctan (r / f)$. The cone output face radius is then set equals as the absorber radius $a$. The cone length $L$ and input radius $A$

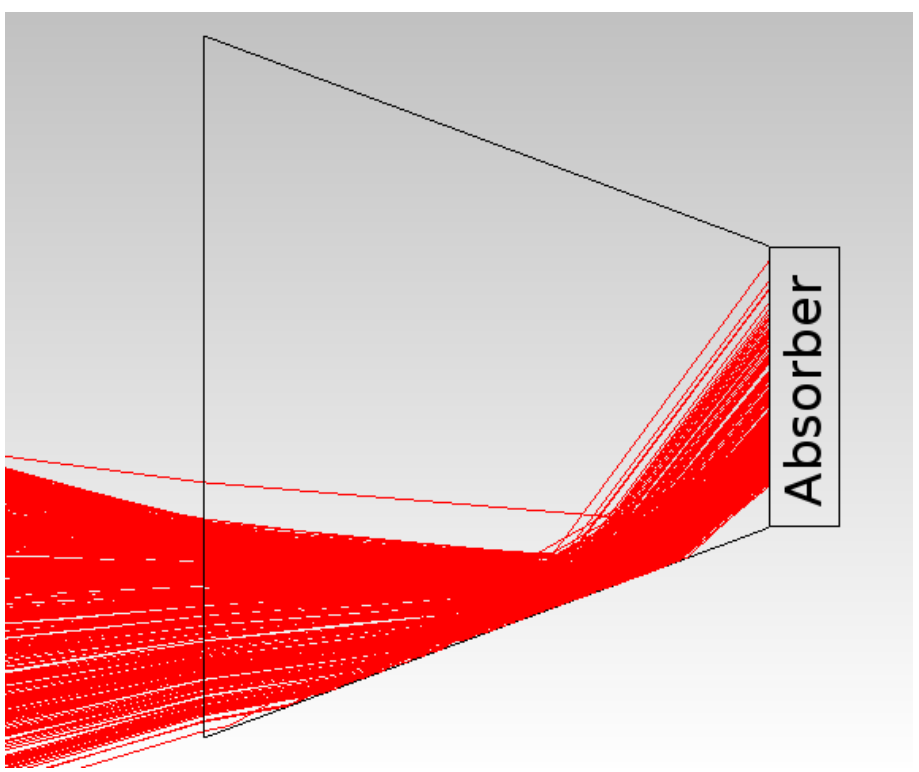

Fig. 6: Collection of light focalised by a Fresnel lens for a $1^{\circ}$ incidence by a cone.

are defined finally by the edge ray method as shown on Figure 5 :

$$
\begin{gathered}
L=\frac{2 a}{\tan \theta_{f}^{\prime}-\tan \alpha} \\
A=L \tan \alpha+a
\end{gathered}
$$

The definition of the cone parameters $A, a, L$ and $\alpha$ here ensure that all the rays focalized by the lens exit the cone with a maximum angle of $\theta_{f}$.

To increase the CPV efficiency and lower the cost, the goal is to increase the concentration ratio and decrease the absorber surface. We chose here an absorber radius of $a=2 \mathrm{~mm}$ and an output angle $\theta_{f}$ of $75^{\circ}$. The focal length of the Fresnel lens is chosen as $150 \mathrm{~mm}$ to keep a compact concentrator setup and limit the focal displacement versus incidence angle (Figure 3). The focal spot radius is estimated to $w=2 \mathrm{~mm}$, with the impact of the incidence angle of $\Delta w=3 \mathrm{~mm}$ for $1^{\circ}$, the cone input diameter must be larger than $A>=5 \mathrm{~mm}$ to be able to collect all the incident rays. With a cone made of glass $\left(n_{c}=1.5\right)$ and a Fresnel lens radius of $r=50 \mathrm{~mm}$, the cone length $L$ is $8.03 \mathrm{~mm}$ long to keep an angle $\alpha$ of $20.41^{\circ}$. This setup has been simulated (Figure 6) and results in an efficiency as high as $87.7 \%$, with maximum output angles of $80^{\circ}$ and a tolerance of $\pm 1^{\circ}$ on the incident rays.

\section{Conclusion}

This study concerns some important characteristics of two solar concentration setups based on a Fresnel lens with a CPC or a cone. It is shown that the focal point displacement versus the incidence angle is important and must be taken into account during the design of the secondary optical element. Also, a detailed procedure for the cone design is presented, and results show that even the primary optic size can be limited by the cone acceptance angle. 


\section{REFERENCES}

[1] http://www.nrel.gov/ (visited on 01/09/2014)

[2] http://www.laserfocusworld.com/articles/print/volume-48/issue12/features/photovoltaics-takes-small-steps-on-journey-to-greaterefficiency.html (visited on 01/09/2014)

[3] A. Rabl, Comparison of solar concentrators, Sol. Energy, vol. 18, pp. $93-$ 111,1976

[4] F. Muhammed-Sukki, R. Ramirez-Inguez, S. G. McMeekin, B.G. Stewart, B. Clive, "Solar concentrators", IJAS, vol. 1, pp. 1-15, 2010

[5] W.T. Xe, Y.J. Dai, R.Z. Wang, K. Sumathy, "Concentrated solar energy applications using Fresnel lenses: A review", Renew. Sust. Energ. Rev., vol. 15 , pp. $2588-2606,2011$

[6] A. Antonini, M. Stefancich, J. Coventry, A. Parretta, "Modelling of compound parabolic concentrators for photovoltaic applications", International Journal of Optics and Applications, vol. 3, pp. 40-55, 2013

[7] A. Parretta, A. Antonini, "Optics of solar concentrators. Part II: Models of light collection of 3D-CPCs under direct and collimated beams", International Journal of Optics and Applications, vol. 3, pp. 72-102, 2013

[8] M. Victoria, C. Dominguez, I. Antòn, G. Sala, "Compartive analysis of different secondary optical elements for aspheric primary lenses", Opt. Express, vol. 17, pp. 6487-6492, 2009

[9] R. Winston, J.C. Minano, P. Benitez, "Nonimaging optics", Elsevier Academic Press, pp. 50-51, 2005

[10] D.E. Williamson, "Cone Channel Condenser Optics", J. Opt. Soc. Am., vol. 42, pp. 712-714, 1952

[11] G.E. Arnaoutakis, J. Marques-Hueso, T.K. Mallick, B.S Richards, "Coupling of sunlight into optical fibres and spectral dependence for solar energy applications", Sol. Energy, vol. 93, pp. 235-243 2013

[12] S. Kiatgamolchai, E. Chamni, "Theory and experiment of a twodimensional cone concentrator for sunlight", Sol. Energy, vol. 82, pp. 111-117 2008 